\title{
Donor Shortage in Germany: Impact on Short- and Long-Term Results in Liver Transplantation
}

\author{
Gerd Otto \\ Dir. em. of the Department of Hepatobiliary and Transplant Surgery, University Medical Center Mainz, Mainz, Germany
}

\section{Keywords}

Donor shortage - Liver transplantation - Organ donation . Outcome $\cdot$ Survival

\section{Summary}

With slightly more than 10 donors per million inhabitants, Germany belongs to the underdeveloped countries in Europe with regard to organ donation. Organ shortage is supposed to promote the usage of organs which are declined in case of less pronounced scarcity. This may result in deteriorated graft and patient survival. In the light of this situation, data on the centers' procedures and outcome of liver transplantation in Germany is presented based upon reports of Eurotransplant, the German Institutions for Quality Assessment, and the Deutsche Stiftung Organtransplantation. Surprisingly, along with an increasing organ scarcity, the outcome during waiting time and after transplantation has been improved. The 1- and 3-year patient survival improved by 7 and $9 \%$, respectively. Reasons for this unexpected development are discussed.

(c) 2018 S. Karger GmbH, Freiburg

\section{Introduction}

With slightly more than 10 donors per million inhabitants, Germany belongs to the underdeveloped countries in Europe with regard to organ donation. Organ donation peaked in 2010 (15.8 donors per million inhabitants), steadily declined thereafter until 2013, and is stagnating since that time [1]. The decline was interfered by manipulations of laboratory values of patients, leading to

Data from this manuscript have in part been presented at the symposium 'Frontiers in Surgical Evolution' on September 21, 2018 in honor of Prof. Dr. Ernst Klar, Rostock, Germany. irregularities in organ allocation which became apparent in Germany in 2012 but were obviously not caused by them. Parallel to the rate of organ donors, the rate of organ transplantation decreased. The number of liver transplantations (LTs), which are the focus of the present appraisal, using deceased donor grafts declined from 1,187 to 846 transplantations between 2010 and 2015 [2].

What was the result of this aggravating organ scarcity? Organ shortage is supposed to promote the usage of organs which are discarded in case of less pronounced scarcity. In a recently published German multicenter study [3], the median donor risk index (ETDRI) in the years around 2010 was $2.0(1.22-3.6)$ [4]. At that time, the donation rate was comparatively high in Germany. In the entire Eurotransplant (ET) area the ET-DRI was 1.7 at the same time. The usage of grafts with high DRI was supposed to contribute to the $10 \%$ lower survival of LT in Germany [5] when compared to other European countries [6]. As transplant centers could have been urged to use even worse grafts, particularly those with higher donor age, steatosis, and prolonged stay on the intensive care unit, further deterioration of the outcome should be assumed due to the progressive organ shortage. Therefore, we scrutinized listing of patients for transplantation, transplantation rates, and results of LT in Germany along with the decline in organ donation between 2010 and 2015.

\section{Collection of Transplant Data by Different Institutions}

In the absence of a transplant registry, three different organizations collecting data on transplantation need to be considered when transplant data is required: ET, the Deutsche Stiftung Organtransplantation (DSO), and the Institut für Qualität und Transparenz im Gesundheitswesen (IQTIG)/Angewandte Qualitätsförderung und Forschung im Gesundheitswesen (AQUA). These institutions publish reports on a yearly basis which are available on their respective websites. Annual reports were used to provide data on the issues in question. Due to strict regulations of data security,

\section{KARGER}

() 2018 S. Karger GmbH, Freiburg

Fax +497614520714
Prof. Dr. Gerd Otto

Dir. em. of the Department of Hepatobiliary and Transplant Surgery

University Medical Center Mainz

Langenbeckstraße 1, 55131 Mainz, Germany

gerd.otto@ unimedizin-mainz.de 
Fig. 1. Liver donors, livers used, and livers transplanted in Germany 2010-2015 [2].

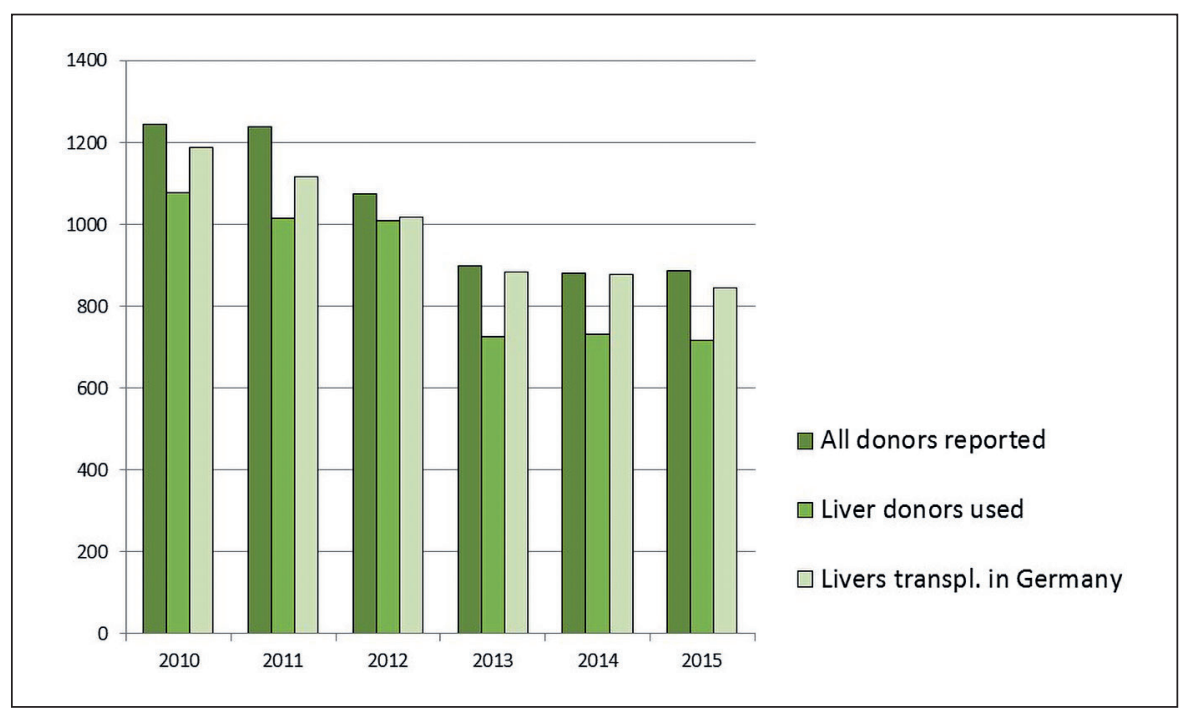

raw data of the registries are not accessible. Accordingly, calculations of statistical significance are not feasible, and this may hamper the explanatory power of this study. The analysis was restricted to the years 2010-2015 since long-term survival (at least 2 years) was only available for that time span.

Data concerning organ donation and used liver grafts originate from the DSO and from ET. Waiting list data were extracted from the annual reports of ET, whereas reliable data on the outcome of LT are solely available in the IQTIG/AQUA reports. In addition, data from the Collaborative Transplant Study, Heidelberg, and from the European Liver Transplant Registry, Paris, are included.

\section{Declining Rates of Organ Donation}

The declining rates of organ donation are demonstrated in figure 1. With 15.8 donors per million (1,296 donors) in 2010, Germany reached the highest donation rate ever. Since 2013, the number of organ donors remained over 850 but declined further to 823 in 2017 (data not shown). The number of livers used for LT was 1,077 in 2010 but decreased to 717 in 2015 . The total number of LTs in 2010 was 1,187, in 2015 it was 846. The greater number of transplanted livers compared to livers donated in Germany is due to the organ exchange between the ET countries, leading to a favorable balance in hepatic grafts for Germany [7]. At the same time, the number of patients listed for LT decreased from 2,120 to 1,489 [8]. Accordingly, the number of patients on the waiting list at the end of the year decreased from 2,161 to 1,280 in the respective years.

Not only the number of listed patients and the transplantations performed during that time span changed but also the fate of patients during waiting time was slightly different: The rate of transplanted patients increased, and the rate of those patients who deceased while being on the waiting list or who were removed from the list due to being unsuitable for transplantation decreased [9] (fig. 2). The time on the waiting list prior to transplantation de- clined from 220 to 125 days, and the interval between listing and death on the waiting list was also shorter (360 vs. 130 days in the respective years). The patients' urgency as reflected by the MELD (Model for End-stage Liver Disease) score was unchanged. The laboratory MELD (labMELD) as well as the matchMELD (standard exceptions) scores were stable at around 21 and 28, respectively.

All survival data is available in the reports of the institutions for quality assessment in Germany (IQTIG or AQUA) [10, 11]). In addition, the DSO reports allow for comparative assessment of different transplant centers, whereas this is not presented in the reports of the institutions for quality assessment [12]. The ratio between the expected and the observed mortality among the German transplant centers is ranging up to factor 2, reflecting considerable differences in outcome. Mean hospital mortality was $16.6 \%$ in 2010 and declined to $12.2 \%$ in 2015. Patient survival after 1 and 3 years improved from 75.5 and $67.9 \%$ in 2010 to 82.5 and $76.9 \%$ in 2014, respectively. The 2-year survival for 2015 was slightly inferior to that of 2014 (78.1 vs. 79.7\%) (fig. 3). By improving patient survival, the difference between other European countries and Germany has been substantially diminished lately [6].

\section{Discussion}

A discussion of the reasons for the unsatisfactory organ donation in Germany is beyond the scope of this article. There is a widespread opinion that organizational problems in identifying potential donors in the peripheral hospitals and in realizing cooperation between all participants in the donation process appear to be crucial. So far, initiatives aiming at improving organ donation in Germany were futile.

Unquestionably, the usage of grafts of poor quality entails worse results [13]. The DRI, including graft features such as donor age, cause of death, cold ischemia time etc., has turned out to be a reliable predictor of graft survival $[3,14]$. In addition, steatotic livers, which are not considered in the DRI calculation, proved to be an 
Fig. 2. Waiting list outcome Germany 2010-2015 [9].
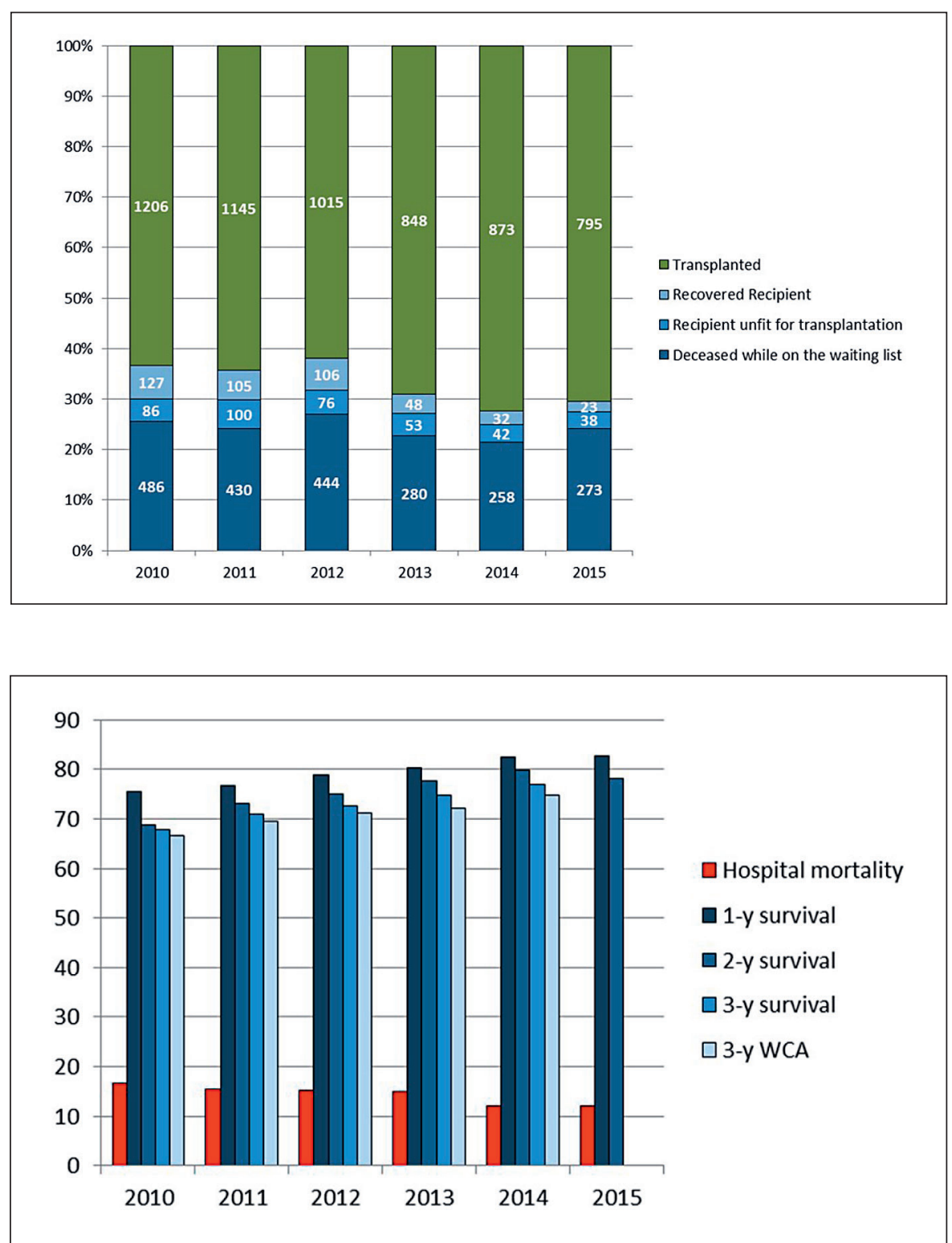

Fig. 3. Short- and long-term survival of liver transplantation in Germany 2010-2015 [10, 11]. $\mathrm{Y}=$ Year; $\mathrm{WCA}=$ worst case analysis.
In Germany, quality control of the centers' performance in LT has been initiated in 2006 and became more and more structured in recent years. Moreover, manipulations of data by several centers which led to unjustified prioritization of patients on the waiting list became apparent in 2012. Thus, the transplant legislation was changed as well as a commission established to perform regular visitations of all transplant programs in Germany [16]. The task of this commission is not quality control but supervision of adherence to the policy regulations which are determined by the German Medical Association.

Not only graft scarcity itself but also, unquestionably, quality management and regular supervising have changed the attitude of the transplant centers towards patient selection, listing, and transplantation. It might be speculated that the transplant physicians became aware that it was harder to get a patient transplanted and that it was therefore decided to restrict the listing of patients to those with a more favorable prognosis. This change of the proce- 
dure resulted in fewer patients being eligible for the waiting list and in removing unsuitable patients from the ET waiting list. This, again, contributed to the decreasing mortality on the waiting list and to higher transplantation rates.

Despite the encouraging development of the outcome of LT in Germany, the entire situation is far from being satisfying. First, the above-mentioned explanations remain speculative. Second and more importantly, the explanations portend another problem: What happened to the patients who are eliminated from the waiting list and to those who are not transplanted due to organ short- age? A large proportion of them will have died but could have been transplanted under more favorable conditions. Altogether, organ shortage in Germany indicates a critical situation which deserves more attention and dedication of the German health system.

\section{Disclosure Statement}

The author did not provide a conflict of interest statement.

\section{References}

1 https://www.dso.de/servicecenter/downloads/jahresberichte-und-grafiken.html.

2 https://www.eurotransplant.org/cms/index. php?page=annual_reports.

3 Otto G, Heise M, Thies J, Pitton M, Schneider J, Kaiser G, Neuhaus P, Kollmar O, Barthels M, Geks J, Bechstein WO, Hellinger A, Klempnauer J, Padberg W, Frühauf N, Ebbing A, Mauer D, Schneider A, Kwiecien $\mathrm{R}$, Kronfeld K: Liver preservation by aortic perfusion alone compared with preservation by aortic perfusion and additional arterial ex situ back-table perfusion with histidine-tryptophan-ketoglutarate solution: a prospective, randomized, controlled, multicenter study. Transplant Direct 2017;3:e183.

4 Braat AE, Blok JJ, Putter H, Adam R, Burroughs AK, Rahmel AO, Porte RJ, Rogiers X, Ringers J: The Eurotransplant donor risk index in liver transplantation: ET-DRI. Am J Transplant 2012;12:2789-2796.
5 www.sqg.de/sqg/upload/CONTENT/Qualitaetsberichte/2010/AQUA-Qualitaetsreport-2010.pdf.

6 www.ctstransplant.org/protected/graphicsSearch. jsp\#RESULTS.

7 https://www.eurotransplant.org/cms/index. php?page=annual_reports.

8 https://www.dso.de/fileadmin/templates/media/Uploads/PDFs/Taetigkeitsberichte_2017/ Grafiken_D_2017_Leber_Inhalt.pdf.

9 http://statistics.eurotransplant.org/index. php?action=login.

10 http://www.sqg.de/sqg/upload/CONTENT/Qualitaetsberichte/.

11 https://iqtig.org/qs-verfahren/ltx/.

12 https://www.dso.de/organspende-und-transplantation/ transplantation/transplantationszentren.html.
Schoening W, Helbig M, Buescher N, Andreou A, Schmitz V, Bahra M, Puhl G, Pascher A, Pratschke J, Seehofer D: Eurotransplant donor-risk-index and recipient factors: influence on long-term outcome after liver transplantation - a large single-center experience. Clin Transplant 2016;30:508-517.

14 Feng S, Goodrich NP, Bragg-Gresham JL, Dykstra DM, Punch JD, DebRoy MA, Greenstein SM, Merion RM: Characteristics associated with liver graft failure: the concept of a donor risk index. Am J Transplant 2006;6:783-790.

15 Spitzer AL, Lao OB, Dick AA, Bakthavatsalam R, Halldorson JB, Yeh MM, Upton MP, Reyes JD, Perkins JD: The biopsied donor liver: incorporating macrosteatosis into high-risk donor assessment. Liver Transpl 2010; 16:874-884.

16 https://www.gesetze-im-internet.de/tpg/TPG.pdf. 